\title{
New Triterpene Glucosides from the Roots of Rosa laevigata $\operatorname{Michx}$
}

\author{
Jing-Quan Yuan ${ }^{1,2}$, Xin-Zhou Yang ${ }^{2}$, Jian-Hua Miao ${ }^{1}$, Chun-Ping Tang ${ }^{2}$, Chang-Qiang Ke ${ }^{2}$, \\ Ji-Bao Zhang ${ }^{2}$, Xiao-Jun Ma ${ }^{1,3, *}$ and Yang Ye ${ }^{2, *}$
}

1 Guangxi Institute of Medicinal Plant, Nanning 530023, P.R. China; E-mail: yjqgx@163.com (J-Q. Y), mjh1962@vip.163.com (J-H. M.)

2 State Key Laboratory of Drug Research, Shanghai Institute of Materia Medica, Chinese Academy of Sciences, Shanghai 201203, P.R. China; E-mail: xinzhou.yang@unibas.ch (X-Z. Y.), tangcp_sh@163.com (C-P. T.), cqke@mail.shcnc.ac.cn (C-Q. K.)

3 Institute of Medicinal Plant Development, Chinese Academy of Medical Sciences and Peking Union Medical College, Beijing 100094, P.R. China

* Authors to whom correspondence should be addressed; E-mails: xjma@public.bta.net.cn (X-J. M.); yye@mail.shcnc.ac.cn (Y. Y.); Tel: +86-7715604464 (X-J. M.); +86-215-0806726 (Y. Y.); Fax: +86- 7715604464 (X-J. M); +86-215-0806726 (Y. Y.).

Received: 18 August 2008; in revised form: 11 September 2008 / Accepted: 12 September 2008 / Published: 22 September 2008

\begin{abstract}
Two new ursane-type triterpene glucosides, $2 \alpha, 3 \alpha, 24$-trihydroxyurs-12,18-dien28-oic acid $\beta$-D-glucopyranosyl ester (1) and 2 $\alpha, 3 \alpha, 23$-trihydroxyurs-12,19(29)-dien-28oic acid $\beta$-D-glucopyranosyl ester (2), were isolated from the roots of Rosa laevigata, together with three known compounds: $2 \alpha, 3 \beta, 19 \alpha$-trihydroxyurs-12-en-28-oic acid $\beta$-Dglucopyranosyl ester (3), $2 \alpha, 3 \alpha, 19 \alpha$-trihydroxyurs-12-en-28-oic acid $\beta$-D-glucopyranosyl ester (4) and $2 \alpha, 3 \beta, 19 \alpha, 23$-tetrahydroxyurs-12-en-28-oic acid $\beta$-D-glucopyranosyl ester (5). The structures of new compounds were established on the basis of detailed 1D and 2D NMR spectroscopic analyses. Compounds $\mathbf{2}$ and $\mathbf{5}$ exhibited modest in vitro antifungal activities against Candida albicans and C. krusei.
\end{abstract}

Keywords: Ursane-type triterpene glucosides; Rosa laevigata; Antifungal activity 


\section{Introduction}

Rosa laevigata Michx. (Rosaceae), an evergreen climbing shrub, is widely distributed throughout southern China [1]. Its fruits, known as a commonly used traditional Chinese medicine (TCM) 'JinYing-Zi', are prescribed in the Chinese Pharmacopoeia for the treatment of wet dreams, urinary incontinence, urinary frequency, uterine prolapse, menstrual irregularities and leucorrhea [1, 2]. The roots of this plant are used in folk practices of Hunan, Guangdong and Guangxi provinces to cure pelvic inflammation, ascending infection, irregular vaginal bleeding, cervical erosion, and cervicitis [1, $3]$. In addition, the roots of $R$. laevigata are an essential constituent of three famous proprietary TCMs, i.e., San-Jin-Pian, Jin-Ji-Jiao-Nang, and Fu-ke-Qian-Jin-Pian. These proprietary TCMs focus on the treatment of gynecological infection and diseases of urinary system. No chemical constituent except tannins has been reported from the roots $[4,5]$. As a part of our in vitro antimicrobial screening efforts, the EtOAc fraction of the EtOH extract from the roots of $R$. laevigata showed good antifungal activities against Candida albicans, C. krusei, and C. parapsilosis. Bioassay-guided fractionation led to the isolation of two new ursane-type triterpenoids, $2 \alpha, 3 \alpha, 24$-trihydroxyurs-12,18-dien-28-oic acid $\beta$ D-glucopyranosyl ester (1) and 2 $\alpha, 3 \alpha, 23$-trihydroxyurs-12,19(29)-dien-28-oic acid $\beta$-D-glucopyranosyl ester (2), together with three known compounds, $2 \alpha, 3 \beta, 19 \alpha$-trihydroxyurs-12-en-28-oic acid $\beta$-Dglucopyranosyl ester (3) [6], $2 \alpha, 3 \alpha, 19 \alpha$-trihydroxyurs-12-en-28-oic acid $\beta$-D-glucopyranosyl ester (4) [7, 8] and $2 \alpha, 3 \beta, 19 \alpha, 23$-tetrahydroxyurs-12-en-28-oic acid $\beta$-D-glucopyranosyl ester (5) [7]. Compounds 2 and 5 exhibit modest antifungal activities against $C$. albicans and $C$. krusei. Here, we describe the isolation and structural elucidation of these two new triterpene glucosides, as well as results of antimicrobial tests for all the isolated compounds.

\section{Results and Discussion}

Compound 1 was isolated as an amorphous powder. The molecular formula $\mathrm{C}_{36} \mathrm{H}_{56} \mathrm{O}_{10}$ was established from the quasi-molecular ion $[\mathrm{M}+\mathrm{Na}]^{+}$at $\mathrm{m} / \mathrm{z} 671.3779$ in the HR-ESI-MS. The IR absorptions at 3428, 1731 and $1645 \mathrm{~cm}^{-1}$ indicated the presence of hydroxyl, carbonyl and olefinic groups, respectively. The UV spectrum showed the absorption of a heteroannular diene at $220 \mathrm{~nm}$ [9].

The ${ }^{1} \mathrm{H}-\mathrm{NMR}$ spectrum of $\mathbf{1}$ (Table 1) displayed signals corresponding to five tertiary methyls at $\delta_{\mathrm{H}}$ $0.98,1.05,1.14,1.68$, and 1.71 , a secondary methyl at $\delta_{\mathrm{H}} 1.03$, an olefinic proton at $\delta_{\mathrm{H}} 5.61$ (br. s) and oxygenated methine and methylene protons, ascribed to a sugar moiety. The ${ }^{13} \mathrm{C}-\mathrm{NMR}$ spectrum showed 36 signals, including 6 primary, 10 secondary, 11 tertiary, and 9 quaternary carbons. These NMR data suggested that 1 was a triterpene monoglycoside. A careful analysis of the ${ }^{1} \mathrm{H}-$ and ${ }^{13} \mathrm{C}$ NMR data, assigned to the aglycon moiety from its ${ }^{1} \mathrm{H}-{ }^{1} \mathrm{H}$ correlated spectroscopy $\left({ }^{1} \mathrm{H},{ }^{1} \mathrm{H}\right.$ COSY), heteronuclear single quantum coherence (HSQC), and ${ }^{1} \mathrm{H}$-detected heteronuclear multiple-bond correlation (HMBC) spectra, suggested that the aglycon was an ursane-type triterpenoid with a heteroannular diene, three hydroxyls and a carboxyl group (C-28). The heteroannular diene was assigned at $\mathrm{C}-12(13)$ and $\mathrm{C}-18(19)$ by the $\mathrm{HMBC}$ correlation from the olefinic proton at $\delta_{\mathrm{H}} 5.61$ to the carbon at $\delta_{\mathrm{C}} 135.2(\mathrm{C}-18)$, as well as the correlations from the methyls at $\delta_{\mathrm{H}} 19.5$ and 18.6, assigned to $\mathrm{CH}_{3}-29$ and $\mathrm{CH}_{3}-30$, respectively, to the same carbon at $\delta_{\mathrm{C}} 133.7$ (C-19) (Figure 1). Two oxymethine protons at $\delta_{\mathrm{H}} 4.46$ and 4.60 were observed to correlate to carbons $\mathrm{C}-10$ and $\mathrm{C}-1$, respectively, suggesting that the two hydroxyls were attached to C-2 and C-3. Similarly, the third hydroxyl was 
determined to be located at $\mathrm{C}-24$ by the $\mathrm{HMBC}$ correlation from $\mathrm{CH}_{3}-23$ to the oxymethylene carbon (C-24). The sugar moiety was determined to be a D-glucose based on the coupling constants of each proton and the carbon chemical shifts. It was verified by a complete acid hydrolysis with $\mathrm{HCl}$ and then comparison with an authentic sample by GC analysis. The chemical shift of the anomeric proton at $\delta_{\mathrm{H}}$ $6.27(\mathrm{~d}, J=7.8 \mathrm{~Hz})$ revealed that the glucose was attached to the carbonyl carbon at $174.8(\mathrm{C}-28)$. This was confirmed by a long-range correlation between the anomeric proton and the carbonyl carbon. The relative stereochemistry of 1 was established by analysis of its coupling constants and ROESY data (Figure 2). The ROESY correlation between $\mathrm{CH}_{3}-23$ and $\mathrm{H}-5$ showed the methyl at $\mathrm{C}-23$ was $\alpha$ oriented, and thus the hydroxylmethylene group was in the $\beta$-orientation. The signal of H-2 was observed as a $d d d$ splitting with the coupling constants of $10.5,4.3$ and $3.2 \mathrm{~Hz}$, respectively, indicating a diaxial and two axial-equatorial couplings. Furthermore, the coupling constant of $3.2 \mathrm{~Hz}$ between $\mathrm{H}$ 2 and $\mathrm{H}-3$ revealed an axial-equatorial coupling. Thus, the orientations of both $2-\mathrm{OH}$ and $3-\mathrm{OH}$ were defined as $2 \alpha, 3 \alpha$, which was confirmed by the ROESY correlations from $\mathrm{H}-2$ and $\mathrm{H}-3$ to $\mathrm{CH}_{2}-24$. Therefore, the structure of 1 was determined to be $2 \alpha, 3 \alpha, 24$-trihydroxyurs-12,18-dien-28-oic acid $\beta$-Dglucopyranosyl ester.

Figure 1. The structures of compounds 1-5.

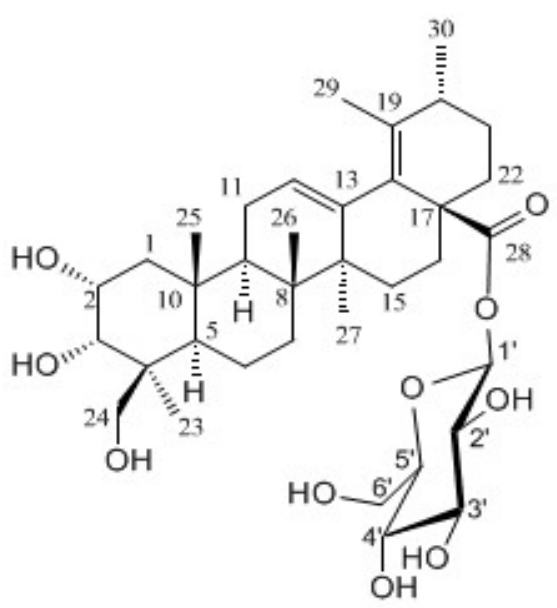

1

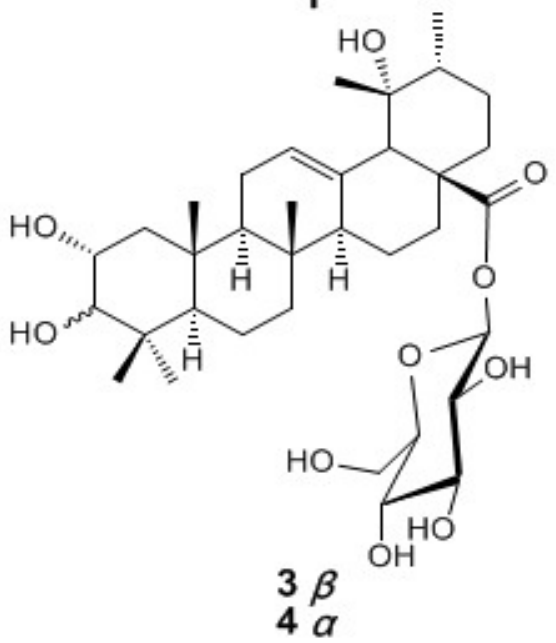

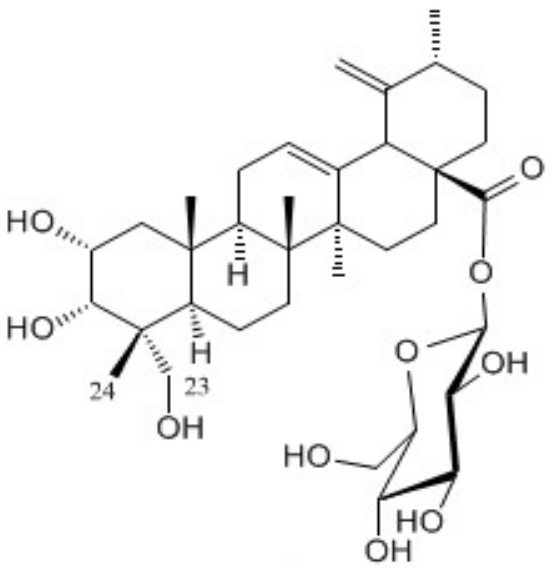

2

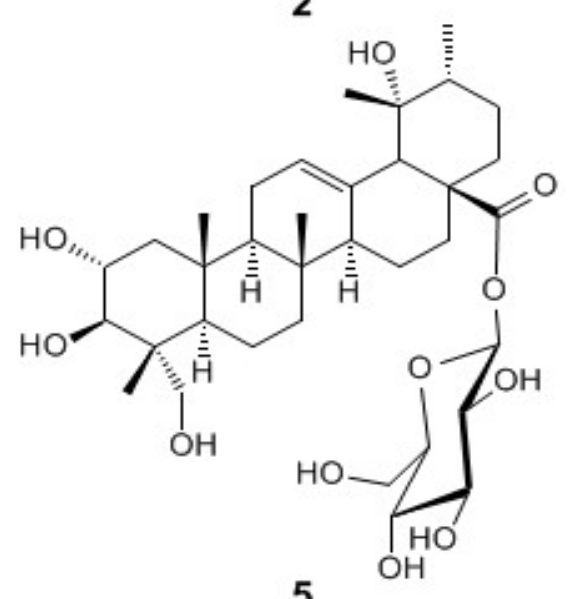


Table 1. ${ }^{1} \mathrm{H}-(600 \mathrm{MHz})$ and ${ }^{13} \mathrm{C}-(150 \mathrm{MHz}) \mathrm{NMR}$ data for $\mathbf{1}$ and 2 (in Pyridine- $\left.d_{5}\right)$.

\begin{tabular}{|c|c|c|c|c|}
\hline \multicolumn{3}{|c|}{1} & \multicolumn{2}{|l|}{2} \\
\hline & $\delta_{\mathrm{H}}(J \mathrm{~Hz})$ & $\delta_{\mathrm{C}}$ & $\delta_{\mathrm{H}}(J \mathbf{H z})$ & $\delta_{\mathrm{C}}$ \\
\hline 1 & $1.84, \mathrm{~m} ; 2.04, \mathrm{~m}$ & 43.6 & $1.83, \mathrm{~m} ; 1.93, \mathrm{~m}$ & 42.7 \\
\hline 2 & 4.46, ddd $(10.5,4.3,3.2)$ & 66.2 & 4.27, ddd $(9.7,4.1,2.7)$ & 66.2 \\
\hline 3 & $4.60, \mathrm{~d}(3.2)$ & 74.1 & $4.14, \mathrm{~d}(2.7)$ & 78.9 \\
\hline 4 & & 44.8 & & 42.9 \\
\hline 5 & $1.78, \mathrm{~m}$ & 48.3 & $2.03, \mathrm{~m}$ & 43.6 \\
\hline 6 & $1.43, \mathrm{~m} ; 1.65, \mathrm{~m}$ & 18.7 & $1.55, \mathrm{~m}$ & 18.3 \\
\hline 7 & $1.49, \mathrm{~m}$ & 35.2 & $1.38, \mathrm{~m}$ & 33.1 \\
\hline 8 & & 39.6 & & 39.9 \\
\hline 9 & $1.85, \mathrm{~m}$ & 49.5 & $2.05, \mathrm{~m}$ & 49.5 \\
\hline 10 & & 38.4 & & 38.4 \\
\hline 11 & $2.04, \mathrm{~m}$ & 23.9 & $2.05, \mathrm{~m}$ & 23.9 \\
\hline 12 & 5.61 , br. s & 126.5 & 5.49, br. s & 128.4 \\
\hline 13 & & 138.6 & & 137.6 \\
\hline 14 & & 45.1 & & 41.9 \\
\hline 15 & $1.23, \mathrm{~m} ; 2.41, \mathrm{~m}$ & 28.9 & $1.10, \mathrm{~m} ; 2.38, \mathrm{~m}$ & 29.0 \\
\hline 16 & $1.62, \mathrm{~m}, 2.57, \mathrm{~m}$ & 35.5 & $1.75, \mathrm{~m} ; 1.86, \mathrm{~m}$ & 25.7 \\
\hline 17 & & 50.3 & & 49.8 \\
\hline 18 & & 135.2 & $3.76, \mathrm{~s}$ & 52.2 \\
\hline 19 & & 133.7 & & 153.3 \\
\hline 20 & $2.03, \mathrm{~m}$ & 34.5 & $1.83, \mathrm{~m}$ & 37.5 \\
\hline 21 & $1.23, \mathrm{~m} ; 2.04, \mathrm{~m}$ & 26.7 & $1.22, \mathrm{~m} ; 1.37, \mathrm{~m}$ & 30.7 \\
\hline 22 & $1.67, \mathrm{~m} ; 2.17, \mathrm{~m}$ & 30.9 & $1.79, \mathrm{~m} ; 1.94, \mathrm{~m}$ & 37.1 \\
\hline 23 & $0.98, \mathrm{~s}$ & 65.1 & $3.73, \mathrm{~d}(10.2) ; 3.88, \mathrm{~d}(10.2)$ & 71.2 \\
\hline 24 & $3.80, \mathrm{~m} ; 4.12, \mathrm{~m}$ & 21.9 & $0.85, \mathrm{~s}$ & 17.7 \\
\hline 25 & $1.05, \mathrm{~s}$ & 17.8 & $1.02, \mathrm{~s}$ & 17.2 \\
\hline 26 & $1.14, \mathrm{~s}$ & 18.4 & $1.14, \mathrm{~s}$ & 17.4 \\
\hline 27 & $1.68, \mathrm{~s}$ & 23.8 & $1.12, \mathrm{~s}$ & 26.2 \\
\hline 28 & & 174.8 & & 176.1 \\
\hline 29 & $1.71, \mathrm{~s}$ & 19.5 & 4.95 , br. s; 5.10 , br. s & 110.4 \\
\hline 30 & $1.03, \mathrm{~d}(7.0)$ & 18.6 & $1.02, \mathrm{~d}(7.0)$ & 19.4 \\
\hline Glc & & & & \\
\hline $1^{\prime}$ & $6.27, \mathrm{~d}(7.8)$ & 95.9 & $6.29, \mathrm{~d}(8.3)$ & 95.9 \\
\hline $2^{\prime}$ & $4.18, \mathrm{dd}(8.3,7.8)$ & 74.0 & $4.21, \mathrm{dd}(8.8,8.3)$ & 74.0 \\
\hline $3^{\prime}$ & $4.27, \mathrm{~m}$ & 78.8 & $4.28, \mathrm{~m}$ & 78.9 \\
\hline $4^{\prime}$ & $4.35, \mathrm{~m}$ & 71.1 & $4.34, \mathrm{dd}(9.3,9.2)$ & 71.1 \\
\hline $5^{\prime}$ & $3.98, \mathrm{~m}$ & 79.1 & $4.03, \mathrm{~m}$ & 79.3 \\
\hline $6^{\prime}$ & $4.37, \mathrm{~m} ; 4.46, \mathrm{~m}$ & 62.2 & $4.37, \mathrm{~m} ; 4.47, \mathrm{~m}$ & 62.2 \\
\hline
\end{tabular}

Compound 2 was also isolated as an amorphous powder. The molecular formula was established as $\mathrm{C}_{36} \mathrm{H}_{56} \mathrm{O}_{10}$, the same as that of $\mathbf{1}$, by the HR-ESI-MS spectrum. Its UV, IR and ${ }^{1} \mathrm{H}-\mathrm{NMR}$ spectra strongly resembled those of $\mathbf{1}$, suggesting that 2 shared the same structural skeleton with $\mathbf{1}$. The ${ }^{1} \mathrm{H}-$ NMR spectrum of 2 (Table 1) showed the characteristic signals for an exo-methylene at $\delta_{\mathrm{H}} 4.95$ (br. s) and 5.10 (br. s), instead of a tertiary methyl in 1, which indicated that the double bond was transferred 
from C-18(19) to C-19(29) [10]. Another difference observed was the chemical shift value of C-23, which downfield shifted to $\delta_{\mathrm{C}} 71.2$ in 2 instead of $\delta_{\mathrm{C}} 65.1$ in 1. This evidence suggested that the configuration of $\mathrm{CH}_{3}-24$ in $\mathbf{2}$ might be opposite to that in $\mathbf{1}$. The relative stereochemistry of $\mathbf{2}$ was also established by analysis of its coupling constants and ROESY data (Figure 2). The ROESY correlations (Figure 2) between $\mathrm{CH}_{2}-23$ at $\delta_{\mathrm{H}} 3.88(\mathrm{~d}, J=10.2 \mathrm{~Hz})$ and $3.73(\mathrm{~d}, J=10.2 \mathrm{~Hz})$ and $\mathrm{H}-5$ at $\delta_{\mathrm{H}} 2.03(\mathrm{~m})$ revealed that the hydroxylmethylene exhibited $\alpha$-oriented, and $\mathrm{CH}_{3}-24$ was then $\beta$-oriented. Signals corresponding to $\mathrm{H}_{2}-1, \mathrm{H}-2$ and $\mathrm{H}-3$ showed the similar chemical shifts and the same multiplicities as $\mathbf{1}$ in the ${ }^{1} \mathrm{H}-\mathrm{NMR}$ spectrum, indicating that $\mathbf{2}$ has the same $2 \alpha, 3 \alpha$ oriented hydroxyls as $\mathbf{1}$. The ROESY correlations from $\mathrm{H}-2$ and $\mathrm{H}-3$ to $\mathrm{CH}_{3}-24$ further supported this stereochemistry assignment. Complete acid hydrolysis with $\mathrm{HCl}$ yielded D-glucose, which was determined by GC analysis. Thus, the structure of $\mathbf{2}$ was established as $2 \alpha, 3 \alpha, 23$-trihydroxyurs-12,19(29)-dien-28-oic acid $\beta$-Dglucopyranosyl ester.

The known compounds 3-5 were identified by comparison with the NMR and MS data with the literature values [6-8].

Figure 2. Key HMBC $(\mathrm{H} \longrightarrow \mathrm{C})$ correlations for $\mathbf{1}$ and $\mathbf{2}$.

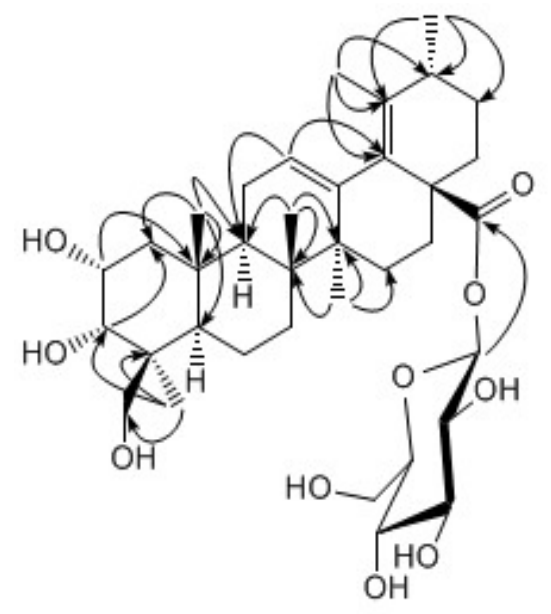

1

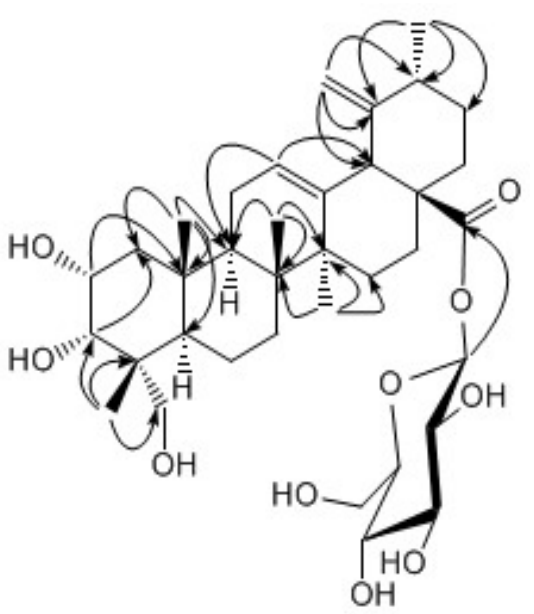

2

\section{Biological activity}

All the isolates were subjected to the dilution assay for in vitro antimicrobial activities against Staphylococcus aureus (ATCC 25923), S. epidermidis (ATCC 26069), Bacillus subtilis (ATCC 6633), Escherichia coli (ATCC 25922), Candida albicans (ATCC 64550), C. krusei (ATCC 6258), C. parapsilosis (ATCC 22019), Klebsiella pneumoniae, Torulopsis glabrata, and Cryptococcus neoformans. The tests were carried out according to the protocols described in the literature [11]. $K$. pneumoniae, T. glabrata and C. neoformanin were obtained from Huashan Hospital, Shanghai, P. R. China. Two antimicrobial agents, chloroamphenicol and fluconazole, were used as positive controls in these tests. Among the tested compounds, compounds $\mathbf{2}$ and $\mathbf{5}$ showed modest antifungal activities against $C$. albicans and $C$. krusei with MIC $12.5-25 \mu \mathrm{g} / \mathrm{mL}$ (Table 2). It was observed that the presence of the hydroxymethylene group at C-23 in the ursane-type triterpenoid has a substantial contribution to the antifungal activity. Compounds $\mathbf{2}$ and $\mathbf{5}$ (containing such a $23 \alpha$-hydroxymethylene 
group) show stronger antifungal activity than compound 1 (24 $\beta$-hydroxymethylene group) or compounds 3 and $\mathbf{4}$ (without such functional groups at C-23 positions).

Table 2. MIC ${ }^{\text {a }}$ Values of 1-5 for Antimicrobial Activities $(\mu \mathrm{g} / \mathrm{mL})$.

\begin{tabular}{|c|c|c|c|c|c|c|c|}
\hline & 1 & 2 & 3 & 4 & 5 & $\begin{array}{c}\text { Chloroamphenico } \\
\text { l }\end{array}$ & Fluconazole \\
\hline S. aureus & 100 & 100 & $>200$ & $>200$ & $>200$ & 4.0 & \\
\hline S. epidermidis & $>200$ & $>200$ & 100 & $>200$ & $>200$ & 4.0 & \\
\hline B. subfitis & 100 & 50 & 100 & $>200$ & $>200$ & 8.0 & \\
\hline E. coli & $>200$ & 100 & $>200$ & $>200$ & $>200$ & 2.0 & \\
\hline K. pneumoniae & $>200$ & 100 & $>200$ & $>200$ & $>200$ & 1.5 & \\
\hline C. albicans & 100 & 12.5 & 100 & 100 & 25 & & 1.56 \\
\hline C. krusei & 50 & 12.5 & 50 & $>200$ & 12.5 & & 50 \\
\hline C. parapsilosis & $>200$ & 50 & 100 & $>200$ & 200 & & 1.56 \\
\hline T. glabrata & $>200$ & $>200$ & $>200$ & $>200$ & $>200$ & & $6.25-12.5$ \\
\hline C. neoformans & $>200$ & $>200$ & $>200$ & $>200$ & $>200$ & & 50 \\
\hline
\end{tabular}

${ }^{\mathrm{a}} \mathrm{MIC}$ was defined as the lowest concentration that inhibited visible growth.

Pentacyclic triterpenoids are distributed widely in plants and reported to exhibit extensive bioactivities, such as antimicrobial, anti-tumor, and anti-HIV properties. In this study, ursane-type triterpene glucosides 1-5 were identified from the roots of $R$. laevigata, and compounds 2 and 5 showed moderate antifugal activities. As the main components, they can account for the bioactivity of the EtOAc extract to some extent. These compounds are the chemical constituents reported for the first time from this part of $R$. laevigata except for tannins. They can be further considered as the chemical fingerprints of this folk medicine.

Figure 3. Key ROESY $(\longleftrightarrow$ ) correlations for $\mathbf{1}$ and $\mathbf{2}$.

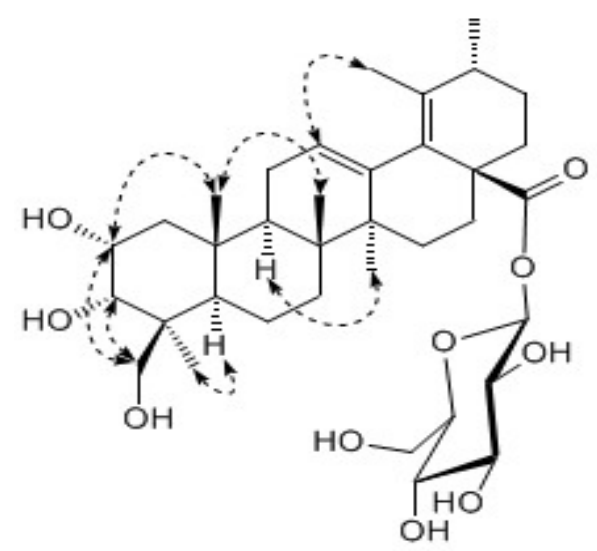

1

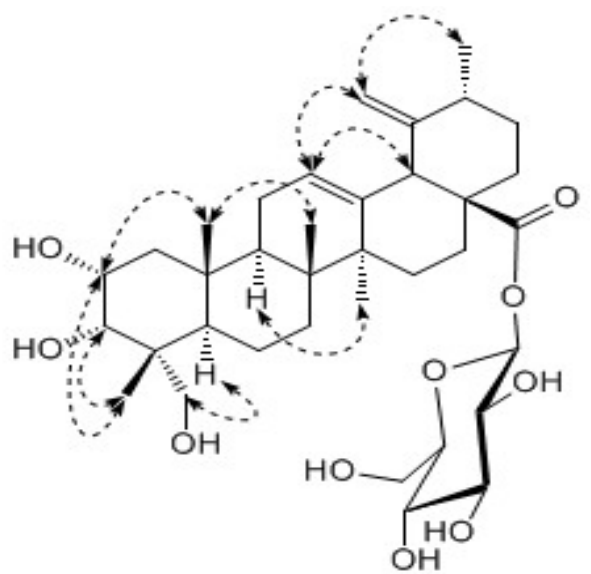

2 


\section{Experimental}

\section{General}

Column chromatography (CC): silica gel (Qing Dao Hai Yang Chemical Group Co.; 200-300 and 300-400 mesh), polyamide resin (Tai Zhou Si Jia Sheng Hua Chemical Group Co., 100-200 mesh), and MCI-gel CHP20P (75-150 $\mu \mathrm{m}$, Mitsubish Chemical Industries, Ltd.). TLC and preparative TLC: precoated silica gel plates (Yan Tai Zi Fu Chemical Group Co.; GF-254). Preparative and Semipreparative HPLC system: two PrepStar SD-1 solvent delivery modules, a ProStar UV-Vis 320 detector and a ProStar 701 Fraction Collector (Varian, Walnut Creek, CA, USA); a LiChrospher 100 RP-18 (Merck, Darmstadt, Germany) column $(220 \times 25 \mathrm{~mm}$ i.d., $12 \mu \mathrm{m})$ was used for preparative isolation. M.p.: Fisher-Johns melting point apparatus; uncorrected. Optical rotation: Perkin-Elmer 341 polarimeter. UV Spectra: Hewlett-Packard 8452A diode array spectrophotometer, $\lambda_{\max }$ in $\mathrm{nm}$. IR Spectra: Nicolet Magna-FT-IR-750 spectrometer, $v_{\max }$ in $\mathrm{cm}^{-1} .{ }^{1} \mathrm{H}$ - and ${ }^{13} \mathrm{C}-\mathrm{NMR}$ Spectra: Bruker DRX-400 and Varian Unity Inova $600 \mathrm{MHz}$ spectrometers; chemical shifts $\delta$ in ppm, with residual Pyridine- $d_{5}$ as internal standard, coupling constant $J$ in $\mathrm{Hz}$, assignments supported by ${ }^{1} \mathrm{H},{ }^{1} \mathrm{H}$ COSY, HSQC, ROESY and HMBC experiments. ESI-MS and HR-ESI-MS: Q-TOF Micro mass spectrometer in $m / z$. Gas chromatography: Shimadzu GC 14-BPF apparatus equipped with a 5\% OV225/AWDMCS-Chromosorb W (80-100 mesh) column $(2.5 \mathrm{~m} \times 3 \mathrm{~mm})$ and a hydrogen-flame ionization detector.

\section{Plant Material}

The dried roots of $R$. laevigata were purchased from Nanning Yixin Pharmaceuticals Ltd., Guangxi, P.R. China in September 2006, and identified by Prof. Chao-liang Zhang of Guangxi Botanical Garden of Medicinal Plants. A voucher specimen (2006047) was deposited in the Herbarium of Shanghai Institute of Materia Medica, Chinese Academy of Sciences.

\section{Extraction and Isolation}

Dried roots of $R$. laevigata $(3.0 \mathrm{~kg})$ were mechanically powdered and percolated with $95 \% \mathrm{EtOH}$ three times $\left(5 \mathrm{~L}\right.$ each) at room temperature. The extract was filtered and concentrated in vacuo $\left(40^{\circ} \mathrm{C}\right)$ to give an EtOH extract (440 g). The extract was suspended in water, and then partitioned successively with petroleum ether (Pe, b.p. $\left.60-90^{\circ} \mathrm{C}\right), \mathrm{CHCl}_{3}$, EtOAc, and $n-\mathrm{BuOH}$ to afford the Pe $(15.6 \mathrm{~g}), \mathrm{CHCl}_{3}$ $(22.0 \mathrm{~g})$, EtOAc $(223.5 \mathrm{~g})$ and $n$-BuOH fractions $(120.0 \mathrm{~g})$, respectively. The EtOAc fraction $(30 \mathrm{~g})$ was subjected to CC over polyamide resin $(500 \mathrm{~g})$ and eluted with $40 \%, 60 \%, 80 \%$ and $100 \%$ aqueous $\mathrm{EtOH}$ in a step manner. The $40 \% \mathrm{EtOH}$ fraction was subjected to $\mathrm{CC}$ over MCI gel $(100 \mathrm{~mL})$ and eluted with $50 \%, 60 \%, 70 \%$ and $80 \%$ aqueous EtOH to afford subfractions 1.1-1.4. The subfraction 1.2 was chromatographied on a silica gel column and eluted with $\mathrm{CHCl}_{3} / \mathrm{MeOH}$ (7:1) to yield 3 (300 $\mathrm{mg})$ and 4 (124 mg). The subfraction 1.3 afford $5(85 \mathrm{mg})$ by $\mathrm{CC}$ over silica gel eluted with $\mathrm{CHCl}_{3}$ $/ \mathrm{MeOH}$ (10: 1). The $60 \%$ EtOH fraction was subjected to a Sephadex LH-20 column and eluted with $\mathrm{MeOH} / \mathrm{CHCl}_{3}$ (3: 1) to give subfractions 2.1-2.5. The subfraction 2.2 was purified by prep. TLC with 
$\mathrm{CHCl}_{3} / \mathrm{MeOH}(8: 1)$ to yield $1(15 \mathrm{mg})$. The subfraction 2.4 was submitted to preparative HPLC $\left(\mathrm{CH}_{3} \mathrm{CN}\right.$ in $\mathrm{H}_{2} \mathrm{O}$ from $15 \%$ to $\left.70 \%, 150 \mathrm{~min}\right)$ to yield $2\left(11 \mathrm{mg}, t_{R} 95 \mathrm{~min}\right)$.

Compound 1: Amorphous powder, $[\alpha]_{D}^{20}+82.1(c=0.5, \mathrm{MeOH}) ; \mathrm{IR}(\mathrm{KBr}) \mathrm{cm}^{-1}: 3428,2935,1731$, 1645, 1457, 1073, 1030; HR-ESI-MS m/z: $671.3779[\mathrm{M}+\mathrm{Na}]^{+}\left(\right.$Calcd for $\mathrm{C}_{36} \mathrm{H}_{56} \mathrm{NaO}_{10}, 671.3771$ ), ${ }^{1} \mathrm{H}$ - and ${ }^{13} \mathrm{C}-\mathrm{NMR}$ : see Table 1 .

Compound 2: Amorphous powder, $[\alpha]_{D}^{20}+72.4(c=0.5, \mathrm{MeOH})$; UV $\lambda_{\max }(\mathrm{MeOH}) \mathrm{nm}$ : 220; IR $(\mathrm{KBr})$ $\mathrm{cm}^{-1}: 3417,2945,1716,1632,1442,1064,1029$; HR-ESI-MS $m / z: 671.3768[\mathrm{M}+\mathrm{Na}]^{+}$(Calcd for $\left.\mathrm{C}_{36} \mathrm{H}_{56} \mathrm{NaO}_{10}, 671.3771\right) ;{ }^{1} \mathrm{H}-$ and ${ }^{13} \mathrm{C}-\mathrm{NMR}$ : see Table 1.

\section{Determination of the Sugar Components [10]}

Compounds 1-2 (4 mg) in 10\% HCl soln./dioxane $(1: 1,1 \mathrm{~mL})$ was heated separately at $80{ }^{\circ} \mathrm{C}$ for 4 $\mathrm{h}$ in a water bath. The mixture was neutralized with $\mathrm{Ag}_{2} \mathrm{CO}_{3}$, filtered, and then extracted with $\mathrm{CHCl}_{3}$ $(30 \mathrm{~mL})$. The aqueous layer was evaporated, and then the residue was treated with L-cysteine methyl ester hydrochloride $(4 \mathrm{mg})$ in pyridine $(0.5 \mathrm{~mL})$ at $60{ }^{\circ} \mathrm{C}$ for $1 \mathrm{~h}$. After reaction, the solution was treated with acetic anhydride $(3 \mathrm{~mL})$ at $60{ }^{\circ} \mathrm{C}$ for $1 \mathrm{~h}$. Authentic samples were prepared by the same procedure. The acetate derivatives were subjected to $\mathrm{GC}$ analysis to identify the sugars (column temperature $210{ }^{\circ} \mathrm{C}$; injection temperature $250{ }^{\circ} \mathrm{C}$; carrier gas $\mathrm{N}_{2}$ at a flow rate of $25 \mathrm{~mL} / \mathrm{min}$ ). Dglucose $\left(t_{R} 1.8 \mathrm{~min}\right)$ was observed from 1 and $\mathbf{2}$.

\section{Antimicrobial activity}

Ths was determined by the broth dilution technique as previously described [11]. The solutions (maximum concentration) of the compounds (i.e. the compounds that induced zones of inhibition) were prepared in DMSO, serially (2-fold) diluted and $0.5 \mathrm{~mL}$ of each dilution was introduced into a test tube containing $4.4 \mathrm{~mL}$ of Selenite broth; then $0.1 \mathrm{~mL}$ of microbial suspension $\left(5 \times 10^{5} \mathrm{cfu} / \mathrm{mL}\right)$ was added and the mixture was homogenized. The total volume of the mixture was $5 \mathrm{~mL}$, with the test compound concentrations in the tube ranging from 200 to $12.5 \mu \mathrm{g} / \mathrm{mL}$ and those of the standard compounds, i.e. Chloroamphenicol and Fluconazole, ranging from 8.0 to 2.0, and 50 to $1.56 \mu \mathrm{g} / \mathrm{mL}$, respectively. After $24 \mathrm{~h}$ of incubation at $37^{\circ} \mathrm{C}$, the MIC was reported as the lowest concentration of a compound that prevented visible growth.

\section{Acknowledgements}

Financial support from the Ministry of Science and Technology (2004CB518902) and Science and Technology Commission of Shanghai Municipality (036505003) are gratefully acknowledged. The authors thank the Department of Analytical Chemistry of SIMM for all spectral measurements. 


\section{References}

1. Xu, G. J.; He, H. X.; Xu, L. S.; Jin, R. Y. Chinese Materia Medica ("Zhonghua Benchao”); Chinese Medicinal Science \& Technology Publishing House: Beijing, P. R. China, 1998; Vol. 7, p. 223.

2. State Pharmacopoeia Commission of the Ministry of Public Health. Pharmacopoeia of the People's Republic of China 2005; Chemical Industry Press: Beijing, P. R. China, 2005; Vol. 1, p. 153.

3. Department of Health of Guangxi Zhuang Autonomous Region. Guangxi Standard of the Traditional Chinese Medicinal Materials; Guangxi Science \& Technology Press: Nanning, P. R. China, 1992; p. 68.

4. Fang, J. M.; Wang, K. C.; Cheng, Y. S. Steroids and triterpenoids from Rosa laevigata. Phytochemistry 1991, 30, 3383-3387.

5. Yoshida, T.; Tanaka, K.; Chang, X. M; Okuda, T. Dimeric ellagitannins, Laevigatins E, F and G, from Rosa Laevigata. Phytochemistry 1989, 28, 2451-2454.

6. Durham, D. G.; Liu, X. J.; Richards, R. M. E. A triterpene from Rubus pinfaensis. Phytochemistry 1994, 36, 1469-1472.

7. Seto, T.; Tanaka, T.; Tanaka, O.; Naruhashi, N. $\beta$-glucosyl esters of $19 \alpha$-hydroxyursolic acid derivatives in leaves of Rubus species. Phytochemistry 1984, 23, 2829-2834.

8. Zhou, X. H.; Kasai, R.; Ohtani, K.; Tanaka, O.; Nie, R. L.; Yang, C. R.; Zhou, J.; Yamasaki, K. Oleanane and ursane glucosides from Rubus species. Phytochemistry 1992, 31, 3642-3644.

9. Adnyana, I. K.; Tezuka, Y.; Banskota, A. H.; Xiong, Q. B.; Tran, K. Q.; Kadota, S. Quadranosides I-V, new triterpene glucosides from the seeds of Combretum quadrangulare. J. Nat. Prod. 2000, 63, 496-500.

10. Adnyana, I. K.; Tezuka, Y.; Awale, S.; Banskota, A. H.; Tran, K. Q.; Kadota, S. Quadranosides VI-XI, six new triterpene glucosides from the seeds of Combretum quadrangulare. Chem. Pharm. Bull. 2000, 48, 1114-1120.

11. Barrero, A. F.; Moral, J. F.; Lara, A.; Herrado, M. M. Antimicrobial activity of sesquiterpenes from the essential oil of Juniperus thurifera wood. Planta Med. 2005, 71, 67-71.

Sample Availability: Samples of the compounds are available from the authors.

(C) 2008 by the authors; licensee Molecular Diversity Preservation International, Basel, Switzerland. This article is an open-access article distributed under the terms and conditions of the Creative Commons Attribution license (http://creativecommons.org/licenses/by/3.0/). 